as it tends to get soaked with perspiration. On the second day the tube is removed, on the fitth day the stitches are removed, and on the following day the patient can get up and if necessary go about his business but wearing a suspender and a perineal pad.

Four points require attention. 1. Care must be taken not to incise the testicle instead of the hydrocele sac. Usually inspection and palpation leave no doubt on the matter, but if for any reason, such as a thickened sac, the decision is difficult the passage of a hypodermic needle will settle the question without appreciable injury to the testicle. 2. Care must be taken to avoid any injury to the cord or testicle and the most delicate handling only must be practised. 3. All drainage must be arrested and a drain must be left for the escape of any oozing. This latter precaution is, I think, of great importance to prevent hæmatoma of the scrotum and the presence of a tube and its withdrawal on the second day offers no considerable inconvenience. 4 . The scrotum must be kept well up on the pubes during convalescence.

Cairo. NOTE ON A RAPIDLY-GROWING OVARIAN TUMOUR
COMPLICATING PREGNANCY ; OVARIOTOMY; MISCARRIAGE ; RECOVERY.

By Daniel Mowat, M.D. EDIN.

THE following case of an ovarian cyst growing rapidly during pregnancy and its removal verifies the remarks made by Dr. W. Duncan in The LANCET of Feb. 4th, but in this case the patient unfortunately miscarried about two hours after the removal of the cyst, most probably from the too free handling of the uterus.

A woman, aged thirty-one years, who had had two children and one miscarriage, had suffered severely from metrorrhagia for several years. On examination in January, 1890, I found the uterus enlarged and fibroid nodules on the posterior wall. The ovaries were normal in size. In January, 1892, she consulted me and stated that she was about three months pregnant but that she was very large. On examination I found the abdomen much larger on the right side than on the left and dull on percussion. Per vaginam the uterus was enlarged to the fifth month and was pushed to the left side. A cystic swelling somewhat larger than a cocoanut was felt towards the right of the uterus. This swelling was diagnosed to be an ovarian cyst and the patient was strongly advised to go to a hospital for operation as she only had three rooms in a small house and was unable to obtain skilled nursing. This, however, she steadfastly refused to do and she was therefore kept under observation, but the swelling increased so rapidly in size that she was soon unable to leave her bed. As her condition was now serious I asked Dr. Duncan of Stamford-hill to see her. This he kindly did and he confirmed my previous diagnosis and expressed the opinion that an operation must be performed at once. To relieve the immediate distress I tapped the cyst, but owing to the gelatinous nature of its contents nothing came through the cannula.

On March 31st Mr. Reynolds of Highgate kindly gave the anæsthetic and Dr. Duncan of Stamford Hill assisted me in the operation. The usual incision in the central line was made and the bleeding vessels were seized at once. The great distension had caused thinning of the integuments and the cyst wall had ruptured at the point where it had previously been tapped. Adhesions had also taken place round this point spreading on the right side into the iliac fossa. These were separated and the tumour was emptied of its gelatinous contents which had to be scooped out with the hand. The tumour which was of the right ovary was then withdrawn, several omental adhesions were separated, and the pedicle was tied in the usual manner and dropped into the abdominal cavity. The pregnant uterus now gradually resumed the normal position in the centre of the abdomen where it immediately began to contract. The peritoneal cavity having been repeatedly washed with warm boric lotion the edges of the incision were brought together with silkworm gut. Two hours after the operation I found the patient in labour and she was shortly delivered of a fœtus six months old. The after pains were very severe but were relieved with morphia. The stitches were removed on the seventh day. $A$ slight attack of phlegmasia alba dolens developed on the seventeenth day which prevented the patient getting about as quickly as she otherwise would have done. The result is very satisfactory, more especially as the operation had been considerably delayed by the patient's refusal to enter a hospital. It was, indeed, only undertaken to save her from impending death. The operation was performed in a small room in a poor locality and the only nursing she had was from her neighbours. Since the operation the patient again became pregnant, but unfortunately miscarried at the fifth month.

Stamford Hill, N.

\section{NOTE ON A CASE OF BRADYCARDIA.}

By Charles Ormerod, M.D. Brux., M.R.C.S. Eng, L R.C.P. LOND.

A MAN, aged 83 years, well-nourished and extremely phlegmatic in disposition, complained of feeling rery cold and of having occasionally what he called a "fit." At these times he turned white and felt faint. The attack was evidently cardiac in character. These attacks occurred on any attempt to get out of bed. The family history of the patient was unimportant. He had had two attacks of rheumatic fever, the second when he was a young man. He had been a non-smoker and had always been very abstemious in his habits. No drugs had any effect on the rate of the heart. On examination the heart dulness was found to extend upwards to the third costal cartilage. Its lateral limits were not markedly increased, the apex beat being in the fifth interspace just inside the nipple. There was a systolic murmur at the apex, inaudible at the back. The heart sounds at the base were natural, but all the sounds were very faint and distant. The pulse was extremely slow. On one occasion only 26 beats and on another 29 beats per minute were counted, but throughout the year during which be has been under my observation the pulse has ranged from 30 to 36 beats per minute. The liver dulness has not obviously increased. There is no albuminuria and no epigastric pulsation. Probably the cause of the extremely slow pulse in this case is some degeneration of the cardiac muscle which is posstbly fatty in nature.

Liphook.

\section{A aftlirtor}

oF

\section{HOSPITAL PRACTICE,} BRITISH AND FOREIGN.

Nulla autem est alia pro certo noscendi via, nisi quamplurimas et. morborum et dissectionum historias, tum aliorum tum proprias
collectas habere, et inter se comparare-MORGAGI De Sed. et .Caus. Morb., lib. iv. Proomium.

\section{ROYAL FREE HOSPITAL.}

A CASE OF SARCOMA OF THE CORPORA CAVERNOSA; REMOVAL; REMARKS.

(Under the care of Mr. W. H. BATTLE.)

IN two points the following case is remarkable. In the first place the disease is one of extreme rarity, very few cases indeed being recorded, and in the second place the long duration of the case is noteworthy, for more than seven and a half years intervened between the first appearance of the disease and the death of the patient. Another point of interest is the enlargement of the breasts ; it is said to occur in cases of malignant disease of the lungs.

The patient, a very tall man, aged 50 years, was first seen in November, 1892. Two years and six months previously he had noticed a difficulty in micturition and six months later a very small swelling appeared in the middle of the perineum. As it gave rise to no pain or inconvenience he took no further notice of it. It increased in size and caused a sensation of weight and also some slight pain on walking. The patient was advised to go into the hospital but be declined; however, in January, 1893, he consented to become an in-patient 